\title{
Mechano-electric Characteristics of the Near-surface Layer of Some Materials
}

\author{
V.M. Yuzevych ${ }^{1, *}$, B.P. Koman², R.M. Dzhala ${ }^{1}$ \\ ${ }^{1}$ Grygoryi Karpenko Physicomechanical Institute National Academy of Science of Ukraine, \\ 5, Naukova st., 79601 Lviv, Ukraine \\ ${ }^{2}$ Franko Lviv National University, 50, Dragomanova st., 79005 Lviv, Ukraine
}

(Received 03 August 2016; revised manuscript received 23 November 2016; published online 29 November 2016)

Based on the proposed mathematical model the mechano-electric characteristics of the near-surface layer of solids included in the linear equation of state and connecting the parameters of states were calculated. Quasiequilibrium condition model of conduction electrons (related charges) on electric double layer on the surface of solid were presented. For the first time, the most important physical quantities to the surface-surface and interfacial charge $\Omega$, the electrical component of the surface energy $\gamma_{e}$, the thickness of the surface layer $h$, electric double layer capacitance $\mathrm{C}$ and Galvani potential $\Delta \Psi$ for a number of materials: $\mathrm{Cr}, \mathrm{W}, \mathrm{Gd}, \mathrm{Hf}, \mathrm{Pd}, \mathrm{Mg}$, Ta, Sm, Si, Cu were calculated. These parameters for the diagnosis of structural elements in aggressive environments can be used and energy characteristics of surface and interfacial layers can be determinated.

Keywords: Modeling, Mechanical stress, Mechanoelectric processes, Surface layer.

DOI: 10.21272/jnep.8(4(1)).04005

PACS numbers: 68.37. Hk, 78.66.Hf, 81.15Ef

\section{INTRODUCTION}

As you know, on the border of metal with inert environment the electric double layers (it's correspond to the gradient of the electron density $(20 \mathrm{~nm})$ ) exists [1]. It's play a decisive role for formation of chemicalreactive properties of solids and interface interaction with other boundary phases. The information about physical properties of electric double layers are essential for creation of multiphase materials with predictable properties. The most important among them is the parameters which were describe the distribution of spatial charges, mechanical stress within the bilayer, surface or interfacial charge etc. and which binds together the relevant parameters of the state equations.

The aim of this work, based on the principles of surface physics and thermodynamics of nonequilibrium processes, the mathematical model of the surface layer taking into account the internal mechanical stress, development of methods for determining its physical constant, included in the equation of state and calculations of the physical characteristics of some typical near-surface layers of materials with different physical and chemical properties: $\mathrm{Cr}, \mathrm{W}, \mathrm{Gd}, \mathrm{Hf}, \mathrm{Pd}$, $\mathrm{Mg}, \mathrm{Ta}, \mathrm{Sm}, \mathrm{Si}, \mathrm{Cu}$ is develop.

\section{THEORETICAL PRECONDITIONS FOR MATHEMATICAL MODELING OF CHARGES DISTRIBUTION AND MECHANICAL STRESS}

\subsection{Research Object}

We formulate one-dimensional correlations for modeling mechanical stress and redistribution of electric charges (free for metals and related to semiconductor or insulator) with $r$ coordinate, where $r$ - radius vector of a point in a spherical coordinate system.The sphere $\left(V_{m}\right.$ area, $\left.r<R\right)$ is placed in a uniform inert gas environment $\left(V_{c}\right.$ area, $r>R$ ), which pressure is equal $p=100 \mathrm{kPa}$. The electric double layer generated conduction electrons and metal ions and located on the sphere surface on the spherical ring, which thickness $h(R>r>R-h)$ [1].

We simulate the metal sphere using two-component homogeneous solid environment consisting of two continuous continuums: the conduction electrons and lattice ions, for which carried out the hypothesis of continuity and local thermodynamic equilibrium $[2,3]$.

The electric double layer is formed on the border of metal (the sphere) and external inert environment. This layer corresponds to the gradient of the electron density in the small border layer (thickness is less than $20 \mathrm{~nm}$ ) [1]. During this process the electric shells of the thin border atoms are deformed. These deformations are manifested in the change of lattice parameters. Based general ideas surface physics and continuum mechanics we put the deformations of atoms in correspondence to the mechanical stresses. Also we consider the distribution of electrical charges and mechanical stress are interrelated. To find the distribution of electrical charges and mechanical stress in a thin surface layer of metal we use Poisson's equation (for electrical charges) of the balance of items of solids and determination of surface tension and energy.

\subsection{Selecting State Parameters}

To describe mechanoelectric distributions in the sphere we consider two pairs of parameters of the thermodynamic state : a) for redistribution of electrical charges - concentration of electrons $C_{e}$, ions $C_{i o n}$ and the chemical potentials $M_{e}, M_{i o n}$ corresponding them (concentrations are dimensionless, dimension of chemical potentials $-\mathrm{J} / \mathrm{kg}$ ); b) for the stressed state - tensors of deformation $\hat{e}$ and mechanical stresses $\hat{\sigma}[2-5]$.

*sonce_28@ukr.net 
These settings we substitute in the extended Gibbs equation for state function $U-$ is internal energy $([U]=\mathrm{J} / \mathrm{kg})[2-4]$ :

$$
d U=T d S+\frac{1}{\rho} \sum_{i, j=1}^{3} \sigma_{i j} \cdot d e_{i j}+M_{e} d C_{e}+M_{i o n} d C_{i o n}
$$

where $S, T$ - entropy and temperature of the local element respectively $\left([S]=\mathrm{J} \cdot(\mathrm{kg} \cdot \mathrm{K})^{-1},[T]=\mathrm{K}\right) ; \cdot \rho-$ specific density of material $\left([\rho]=\mathrm{kg} \cdot \mathrm{m}^{-3}\right) ; e_{i j}, \rho_{i j}-$ components tensors of stresses $\hat{\sigma}$ and deformations $\hat{e}$ $\left(i, j=1,2,3 ;\left[\sigma_{i j}\right]=\mathrm{Pa}\right)$. Given that the mass of the electron by three orders less than the mass of the ion, we can take $d C_{i o n}=0$.

Then we multiply and divide expression $M_{e} \cdot d C_{e}$ by a constant $z_{e}$, where $z_{e}-$ electric charge of unit mass of conduction electrons $\left(\left[z_{e}\right]=\mathrm{Cl} \cdot \mathrm{kg}^{-1}\right)$. Result of multiplication is $C_{e} \cdot z_{e}=\omega=\omega_{V} / \rho$; where $\omega, \omega_{V}$ - specific electric charges of local element calculated per unit mass and unit volume respectively: $\left([\omega]=\mathrm{Cl} \cdot \mathrm{kg}^{-1}\right.$, $\left.\left[\omega_{V}\right]=\mathrm{Cl} \cdot \mathrm{m}^{-3}\right)$. The relation $M_{e} / z_{e}=\Phi=\Phi_{0}+\varphi$ is called modified chemical potential of the conduction electrons $(\mathrm{MCPCE})([\Phi]=[\varphi]=\mathrm{B})$.

In this case, the Gibbs equation (1) can be written (including replacement of multiplication result $\left.M_{e} \cdot d C_{e}=\Phi \cdot d \omega\right)$ for the free energy $\left.F=U-T S-\omega \Phi\right)$ in the form of [2-4]:

$$
d F=-S d T+\frac{1}{\rho} \sum_{i, j=1}^{3} \sigma_{i j} \cdot d e_{i j}+\omega d \Phi
$$

From (2) follow the state equation in general form:

$$
\begin{gathered}
S=-\left.\left(\frac{\partial F}{d T}\right)\right|_{i j}, \Phi=\text { const } \\
\sigma_{i j}=\left.\rho\left(\frac{\partial F}{d e_{i j}}\right)\right|_{T, \Phi=\text { const }} ; \\
\omega=\left.\rho\left(\frac{\partial F}{d \Phi}\right)\right|_{e_{i j}, T=\text { const }}
\end{gathered}
$$

In the next we confine the isothermal case and we aren't considering the state equation for the entropy. Methods for formulating state equations based on relations (2), (3) are shown, for example, in [2-4]. With this purpose usually functional for free energy $\mathrm{F}$ is decomposed in the Taylor series on the state parameters in the neighbourhood of the specified equilibrium state. After that decomposition of the functional limited of second component of decomposition is substituted in (3). Then we are get the linear state equations.

Using the principles of the explained technique, according to (2) and (3), we are obtain linear state equations for tensor components of mechanical stress $\sigma_{i j}$ and density of electric charge $\omega[3-5]$ :

$$
\sigma_{i j}=\left(\left(K-\frac{2}{3} G\right) e-\alpha_{t} K \cdot \Delta T-K b \phi\right) \delta_{i j}+2 G e_{i j},
$$

$$
\omega_{V}=\rho \omega=\rho C_{\phi}\left(\phi-\gamma_{t} \cdot \Delta T\right)+b K e,
$$

where $\delta_{i j}-$ Kronecker symbols; $e=e_{i i} / 3-$ the first invariant of deformations tensor; $\phi=\Phi-\Phi_{0}-$ rejections of the modified chemical potential $\Phi$ of conduction electrons from its equilibrium value $\Phi_{0}$ in the volume of the body away from the surface; $\Delta T=T-T_{0}$ - temperature changes ( $T_{0}$ - temperature values in the initial equilibrium state); $K, G$ - factors of the comprehensive compression and shear; $C_{\phi}$ - specific capacitance; $b$ - electrostrictive coefficient of volume expansion; $\alpha_{t}-$ temperature coefficient of volume expansion; $\gamma_{t}-$ temperature coefficient of changes MCPCE.

\subsection{Galvani Potential}

To analyze the redistribution of the conduction electrons of the neighbourhood of the metal surface we are considering Galvani potential (difference of internal electrical potentials $-\Delta \psi)$. This potential defines difference of the electrical potentials between two points in different phases [6]. These phases can be two different solids (eg, two mechanically connected metals, metal and semiconductor, etc.).

Electrochemical potential $\bar{\mu}_{e}$ for conduction electrons in the metal including definition of $\Phi$ can be represented as $[6,7]$ :

$$
\bar{\mu}_{e}=z_{e}(\Phi+\Psi)
$$

where $\Psi-$ the potential of the electric-field intensity (scalar electric potential). $\psi=\Psi-\Psi_{0}-$ deviations of potential $\Psi$ from its original equilibrium value $\Psi_{0}$ (potential $\Psi$ is defined up to a constant [6]).

If two phases $\alpha$ and $\beta$ have the one common charged particle (for example, electron), then their electrochemical potentials $\bar{\mu}_{e \alpha}$ and $\bar{\mu}_{e \beta}$ are aligned [6] and as the result we get the ratio:

$$
\begin{aligned}
& \bar{\mu}_{e \alpha}=z_{e}\left(\Phi_{\alpha}+\Psi_{\alpha}\right), \quad \bar{\mu}_{e \beta}=z_{e}\left(\Phi_{\beta}+\Psi_{\beta}\right), \\
& \bar{\mu}_{e \alpha}=\bar{\mu}_{e \beta}, \quad \Phi_{\alpha}+\Psi_{\alpha}=\Phi_{\beta}+\Psi_{\beta}, \\
& \Delta \psi=\Psi_{\beta}-\Psi_{\alpha}=\Phi_{\alpha}-\Phi_{\beta}=-\Delta \phi, \quad \Delta \psi+\Delta \phi=0, \\
& \Delta(\psi+\phi)=0, \\
& \Delta\left(\psi+\phi+\Phi_{0}\right)=0, \quad \psi+\phi+\Phi_{0}=\text { const }
\end{aligned}
$$

As in this case, the Galvani potential is determined using difference of chemical potentials $\Delta \psi=\Delta \Psi=\Phi_{\alpha}-\Phi_{\beta}$ (6). This similar to definition of potential difference of MCPCE. Therefore in the further transformations we use $\Delta \psi=-\Delta \varphi$ (symbol $\Delta$ means the deviation of potential).

Using last relations (6. 7) $\psi+\varphi+\Phi_{0}=A=$ const we provide analysis of particular case, when phase $\alpha$ is metal and phase $\beta$ is not electroconductive inert gas environment, which we take $A=0$ (because the electrochemical potential is determined up to a constant).

In the external inert environment (outside sphere in volume $V_{c}$ ) for electric potential $[2,3]$ is: 


$$
\Delta \Psi_{c}=0,
$$

from which follows that $\mathrm{Y}_{c}=A_{c}$, where $A_{c}$ is constant. Taking the electric potential at infinity equal to zero, we obtain $\mathrm{Y}_{c}=A_{c}=0$ in the volume $V_{c}$.

Since the electric potential $\Psi_{\text {on }}$ the border of arbitrary medium is continuous, then for the boundaries of the phase $\alpha$ (on the surface $\Gamma$ ) from (7) follows the limit relation:

$$
\phi+\Phi_{0}=0, \quad \phi=-\Phi_{0},
$$

\section{DETERMINING DISTRIBUTIONS OF ELECTRICAL CHARGES AND MECHANICAL STRESS}

\subsection{Basic Equations of Mechanoelectrics for Metal}

In accordance with the fundamentals of electrostatics and nonequilibrium thermodynamics [4, 5, 7, 8] we can show the electric potential Y using Poisson's equation (10) and the stress tensor we can show as part of the equilibrium equation (11):

$$
\begin{gathered}
\varepsilon \varepsilon_{0} \Delta \Psi=\varepsilon \varepsilon_{0} \Delta \phi=-\rho \omega=-\omega_{V}, \\
\operatorname{Div} \hat{\sigma}+\rho \cdot \omega \cdot \vec{E}=0, \\
\hat{e}=\operatorname{Def} \vec{u},
\end{gathered}
$$

where $\vec{u}-$ is the movement vector in spherical coordinates $\left.\vec{u}=\left(u_{r}, 0,0\right)\right)$, which is associated with the tensor of deformations $\hat{e}$ by the geometric equation (12) [9].

Boundary conditions on the surface $G$ of the distribution of the electroconductive body and inert gas environment, taking into account (8) $[2.3,8]$ can be represented as:

$$
\begin{aligned}
\vec{\sigma}_{n} & =\vec{p}_{c}+\frac{1}{2} \Omega\left(\vec{E}+\vec{E}_{c}\right) ; \Omega=\varepsilon \varepsilon_{0}\left(\left|\vec{E}_{n}\right|-\left|\vec{E}_{c n}\right|\right) ; \\
\Psi & =\Psi_{c} ; \phi=-\Phi_{0} .
\end{aligned}
$$

where $\vec{p}_{c}$ - the environment pressure to the normal $\vec{n}$ to the surface $\Gamma ; \Omega$ - surface charge; $\varepsilon$ - permittivity material; $\vec{E}_{c n}, \vec{E}_{n}$ - components of the electric-field intensity of environment and metal to the normal to the surface $\Gamma$.

The problem of the distribution of electrical charges and the mechanical stresses corresponding them in double electrical layer (4), (5) (10)-(13) we can formulate in a spherical coordinate system $(r, \alpha, \theta)$. For this we move the origin of coordinates in the geometric center of the sphere. Then we obtain:

$$
\begin{aligned}
& \frac{d}{d r}\left[\frac{1}{r^{2}} \cdot \frac{d}{d r}\left(r^{2} u_{r}\right)\right]=\frac{3}{3 K+4 G}\left(\beta K \frac{d \phi}{d r}-\omega_{V} E_{r}\right) \\
& \frac{d^{2} \phi}{d r^{2}}+\frac{2}{r} \cdot \frac{d \phi}{d r}-k^{2} \cdot \phi=\frac{b K}{\varepsilon_{0}} e, \quad\left(k=\sqrt{\frac{\rho \cdot C_{\phi}}{\varepsilon_{0}}}\right)
\end{aligned}
$$

$$
\begin{gathered}
\omega_{V}=\rho \omega=\varepsilon_{0} k^{2} \phi+b K e ; \\
\sigma_{i i}=\left(K-\frac{2}{3} G\right) e-b K \phi+2 G e_{i i} \quad(i=r, \alpha, \theta) ; \\
e=e_{r r}+2 e_{\theta \theta} ; \quad e_{r r}=\frac{d u_{r}}{d r} ; \quad e_{\alpha \alpha}=e_{\theta \theta}=\frac{u_{r}}{r} ; \phi+\psi+\Phi_{0}=c o n s t \\
E_{r}=-\frac{d \psi}{d r}=\frac{d \phi}{d r} ; \quad \Omega=-\varepsilon_{o} E_{r}=\varepsilon_{o} \frac{d \psi}{d r}=-\varepsilon_{o} \frac{d \phi}{d r} ;(18) \\
\phi=-\Phi_{0} ; \quad \sigma_{r r}=-\frac{\varepsilon_{0}}{2} \cdot\left(\frac{\partial \psi}{\partial r}\right)^{2}=\frac{\varepsilon_{0}}{2} \cdot\left(\frac{\partial \phi}{\partial r}\right)^{2}
\end{gathered}
$$

at $r=R$.

\subsection{Method of Determining Distributions $\phi, \sigma_{x}$, $\sigma_{y}$}

Since the expression (14) is nonlinear (expression $\omega_{V} \cdot E_{r}$ is the ponderomotive component), then we are solving the system of equations (14), (15) taking into account (16)-(19) for finding the distributions of potential $\phi$ and mechanical stresses $\sigma_{r}, \sigma_{\theta}$, analytically using the method of small parameter $b_{? *}=b \Phi_{0}$, limiting of the four approximations of the decomposition. Methodics of using the small parameter method for solving problems of mathematical physics is described in [10].

We represent the components $u_{r}$ of movements and $\phi$ (deviation of MCPCE) as series of the small parameter:

$$
\begin{aligned}
& u_{r}=u_{0}+\left(b \cdot \Phi_{0}\right) \cdot u_{1}+\left(b \cdot \Phi_{0}\right)^{2} \cdot u_{2}+ \\
& +\left(b \cdot \Phi_{0}\right)^{3} \cdot u_{3}+\left(b \cdot \Phi_{0}\right)^{4} \cdot u_{4} \\
& \phi=\phi_{0}+\left(b \cdot \Phi_{0}\right) \cdot \phi_{1}+\left(b \cdot \Phi_{0}\right)^{2} \cdot \phi_{2}+ \\
& +\left(b \cdot \Phi_{0}\right)^{3} \cdot \phi_{3}+\left(b \cdot \Phi_{0}\right)^{4} \cdot \phi_{4}
\end{aligned}
$$

Relation for the potential $\phi$ and mechanical stress $\sigma_{r}, \sigma_{\theta}$ we get from (14)-(19) for the area " $V_{m}$ " taking into account the shift $Z_{b}$ of double electric layer relatively border of the body [11]. The results of the solution (14)(19) we write in the abbreviated form:

$$
\begin{gathered}
\sigma_{r}=f_{r}\left(r, b, k, R, \Phi_{0}\right) ; \quad \sigma_{\theta} \approx f_{\theta}\left(r, b, k, R, \Phi_{0}\right) ; \\
\phi=f_{\phi r}\left(r, k, R, \Phi_{0}\right)=-\Phi_{0} \frac{R}{r} \frac{\operatorname{sh}(k r)}{\operatorname{sh}(k R)} ; \\
\Phi_{0}=\frac{q_{0} W_{e}}{2 \varepsilon_{0} k^{2}} \cdot\left(2-\exp \left(-k Z_{b}\right)\right) ; \\
Z_{b}=\frac{3}{4 k_{F}}\left(\frac{\pi}{2}+\left(\frac{5 E_{V}}{3 E_{F}}-1\right) \arcsin \sqrt{\frac{3 E_{F}}{3 E_{F}+5 E_{V}}}-\sqrt{\frac{5 E_{V}}{3 E_{F}}}\right)
\end{gathered}
$$

where $f_{r}, f_{\theta}$ - are symbolizing complex relations which considered four approximations of the small parameter $b \Phi_{0} ; \quad E_{F}-$ Fermi energy; $E_{V}$-electronic 
work from metal; $k_{F}-$ Fermi wave vector; $W_{e}$ - the volume density of the conduction electrons of the metal far from the surface (at a distance of more than $30 \mathrm{~nm}$ ) $\left(\left[W_{e}\right]=\mathrm{m}^{-3}\right) ; q_{0}-$ electron charge.

Shifting $Z_{b}$ of the double electric layer (24) corresponds to the relationship equations (14) and (15). Note that represented above expression (23) for $\Phi_{0}$ is similar to the expression from work [11] derived using the methods of statistical physics. The formula for $\phi$ (23) obtained from the solution of (14)-(21) (including four approximations (21)), and similar to the first relation (23) for $\phi$ including $Z_{b}$ (24) (for sphere with a large radius $R$ ), given in work [11] virtually identical to within corrections, the magnitude of which less than $4 \%$. This indicates that the result of four approximations $\left(\phi_{1}, \phi_{2}, \phi_{3}, \phi_{4}\right)$ for $\phi$ manifested in shifting $Z$. Therefore we can replace the complex expression like (21) using compact relation for $\phi(23)$.

\subsection{Limiting Transition to the Flat Border}

In relations (22), (23) make sense move to the flat distribution border of environments, because effective thicknesses of the double electric layer (surface area) not more than $18 \mathrm{~nm}$ [1.11].

In expressions $(22,23)$ we carry the limiting transition $R \Rightarrow \infty$, where $\sigma_{r} \Rightarrow \sigma_{x}, \sigma_{\theta \theta} \Rightarrow \sigma_{\mathrm{y}}$, and coordinate $r$ corresponds to $x$. Then the resulting relations in abbreviated form become:

$$
\begin{aligned}
\phi= & f_{\phi}\left(x, k, \Phi_{0}\right)=-\Phi_{0} \cdot \exp (-k x) ; \quad \sigma_{y} \approx f_{y}\left(x, b, k, \Phi_{0}\right) ; \\
& \sigma_{x} \approx f_{x}\left(x, b, k, \Phi_{0}\right)=-\frac{1}{2} \varepsilon_{0} \cdot k^{2} \cdot \Phi_{o}^{2} \cdot e^{-2 k x}- \\
& -\frac{1}{2} b \cdot \Phi_{0} \cdot K \cdot \Phi_{*} \cdot e^{-3 k x}-\left(b \cdot \Phi_{0}\right)^{2} \cdot \frac{3 K^{2} e^{-2 k x}}{2(3 K+4 G)}\left(1+\frac{\Phi_{*}}{4} e^{-2 k x}\right)- \\
& -\left(b \cdot \Phi_{0}\right)^{3} \cdot \frac{9 K^{3} e^{-3 k x}}{2(3 K+4 G)^{2}} \times\left(\frac{1}{3}+\frac{\Phi_{*}}{20} e^{-2 k x}\right)- \\
& \left(b \cdot \Phi_{0}\right)^{4} \cdot \frac{9 K^{4}}{8(3 K+4 G)^{3}} e^{-4 k x}\left(1+\frac{1}{10} \Phi_{*} e^{-2 k x}\right)+C_{x},
\end{aligned}
$$

where $f_{y}-$ is the complex relations;

$$
\Phi_{*}=\frac{\varepsilon_{0} \cdot k^{2} \cdot \Phi_{o}^{2}}{3 K+4 G}
$$

\section{THE METHOD OF DETERMINING THE PHYSICAL CHARACTERISTICS OF THE MATERIAL}

\subsection{Representing Systems of Nonlinear Equations}

Traditional approaches to assess of the physical $k, b$ characteristics of the surface layer of metal in the state equations (16), (17) are providing usage approaches of statistical physics or quantum mechanics, which often lead to ambiguous results. The proposed approach uses a method of the decomposition of displacement variables and potential $\phi$ to the small parameter. Also this approach isn't expect explicit usage of theories of statistical physics or quantum mechanics.

Formal expressions for solution of previous problem (25) we are substitute in the system of the four equations $[1,4,5]$, in which the surface tension $\sigma_{h}$ and energy $\gamma$ are defined as:

$$
\begin{gathered}
\int_{0}^{h} \sigma_{y} d x=\sigma_{h}, \quad \sigma_{y}=\sigma_{z}, \\
\gamma_{e}+\xi \gamma_{M}=\gamma, \\
\frac{\partial \gamma}{\partial k}=\frac{\partial\left(\gamma_{e}+\xi \gamma_{M}\right)}{\partial k}=0, \quad\left(k=\sqrt{\frac{\rho C_{\phi}}{\varepsilon_{0}}}\right) \\
\sigma_{y}+p=0(\text { for } x=h)
\end{gathered}
$$

( $p=100 \mathrm{kPa}$ - atmospheric pressure),

where $\gamma_{e}=\int_{0}^{h} w_{e} d x-$ the electrical component of the

surface energy (SE); $\gamma_{m}=\int_{0}^{h} w_{\cdot} d x-$ mechanical

component of SE; $w_{e}=\frac{\varepsilon_{0}}{2}\left(\frac{\partial \Psi}{\partial x}\right)^{2}$ and

$w_{m}=\frac{\sigma_{x}\left(\sigma_{x}-4 v \sigma_{y}\right)}{2 E}+\frac{(1-v) \sigma_{y}^{2}}{E}-$ densities electrical and

mechanical components SE; $h$-effective thickness of the surface layer; $E, v-$ Young's modulus and Poisson's ratio, respectively.

Expressions (26), (27) describing the determination of energy characteristics of surface layers. Relation (28) is a condition of dynamic quasiequilibrium of particles (electrons and ions) that form the double electric layer on the surface of the body. Expression (29) is the condition of the effective thickness of the surface layer. The stresses $\sigma_{y}$ are stretch (positive) in the boundaries of the surface layer, and $p=100 \mathrm{kPa}$ (atmospheric pressure) corresponds to compressive (negative) stresses. Expression $\left|\sigma_{y}\right|=|p|$ gives an opportunity to calculate some distance from the surface $h$, therefore the resulting stress will be zero $\left(\left|\sigma_{y}\right|-|p|=0\right)$.

The system of equations (26)-(29) is applied to the physical characteristics of the materia $\xi, k, b, h$ for the first time. In other works [4, 5] relations (26)-(29) were, but in there them are used for determine the change of surface tension and energy, and $\xi, k, b, h$ are considered constants (defined using methods of statistical physics or quantum mechanics $[1,11,12])$.

\subsection{Features of the Method of Calculation of Physical Quantities $\xi, k, b, h$}

Relations (26)-(29) are a system of equations to determine the physical $\xi, k, b, \Phi_{0}$ and geometric $h$ characteristics of the surface layer. The corresponding algorithm for determining $\xi, k, b, \Phi_{0}, h$ we present in three stages. First step, using the equation of equilibrium of $\hat{\sigma}(14)$ and (15) for $j$, which follows from the Poisson equations, state equation (16), (17) and also boundary conditions (19), we find five approximations of distributions normal mechanical stresses $\sigma_{r}, \sigma_{\theta}$ from coordinate $r$ (in particular, (22)-(24)) using the technique of $[4,10]$ and using method of decomposition $\phi$ and displacements $u_{r}$ in the ranks by the small parameter $b_{\varphi}=b \Phi_{0}(20),(21)$. At the second step, we direct radius $R$ to infinity and obtain analytical 
expressions for $\phi, \sigma_{x}, \sigma_{y}(25)$ depending on the $\mathrm{x}$ and the parameter $k$, not specifying numeric constants for the material. At the third step, we substitute expressions for $\phi, \sigma_{x}, \sigma_{y}$ in the equation (26)-(29). For the system (26)-(29) we must set only numeric values $\sigma_{h}, \gamma, E, v, \rho$, $E_{V}$, which are known from experiment [13-19] and $E_{F}$, $W_{e}$, are obtained from reliable results modeling methods of solid state physics [20] ( $\sigma_{h}$ is determined on the basis of the experiment, and for $\gamma$ is known partial results of experimental studies and theoretical models $[19,20])$.

Thus, at the third stage as a result of calculations (simulation modeling), we get four important physical properties of metal $-\xi, k, b, h$. On these basis we can determine the size and $\Phi_{0}(23)$, through which we are formulating the boundary condition (19) for the modified chemical potential $\phi$ of conduction electrons.

Electric component of surface energy $\gamma_{e}$ we are submit through capacitance of the surface electrical capacitor $C$ and potential (Galvani potential) $\Delta \Psi$ using relations of electrostatics [8]:

$\gamma_{e}=\Omega^{2} /(2 \cdot C)=C \cdot \Delta \Psi^{2} / 2, \quad C=\varepsilon_{0} \cdot k / 2, \quad d=2 / k,(30)$

where $d$-the effective distance between the plates of the capacitor surface (within the double electric layer).

\subsection{The Results of Calculation of Physical Quantities. Checking of Convergence}

The presented algorithm for estimation characteristics of the material $\xi, k, b, h$ tested for $\mathrm{Mg}$, Si, Cr, Fe, Co, Cu, Pd, Ag, Sm, Gd, Hf, Ta, W, Pt, Au. Values of $\sigma, \gamma, E, v, \rho, E_{V}$ were determined by the results of theoretical and experimental studies (mostly known tabular data) [5, 13-20].

It should be noted that the proposed approach for finding $\xi, k, b, h$ can also be applied to semiconductors and dielectrics, but instead the potential $\Phi$ (MCPCE) should be considered potential chemical $Z_{c}$, which correspond to the particles that form the bound electric charge (in this paper for silicon atoms) [8,21]. In addition, a shift of the double electric layer on the surface is not taken into account for these materials. The resulting physical quantities received during calculations using (31) are given in Table 2.

It should be noted that for materials in Tab. 2 the clear laws of changes in the studied parameters for element of $\mathrm{N}$ atomic number in the periodic law or $\mathrm{X}$ electronegativity as is the case for interfacial interaction was missed [4 ]. However, it is typical: 1) the thickness of the surface layer $h$ in all the analyzed material varies slightly and is $\sim 1 \mathrm{~nm}(0,737$ $1,117 \mathrm{~nm})$; 2) the significant changes in the number of investigated elements the surface energy $\gamma_{e}$ was happened, it's due to various input of the electric component under the transition from purely covalent bond (Si-related charges of dipole nature) to pure metallic bond (for example $\mathrm{Cu}, \mathrm{Au}, \mathrm{Cr}, \mathrm{Ta}$ ); 3) the change from element to Galvani potential element was found, it's due to their different valence because of different contribution of conduction electrons in interphase capacitor; 4) the surface charge $\Omega$ decreases naturally is because of the increase of covalent component of the chemical bond and it's reaches minimum in $\mathrm{Si}$.

\section{CONCLUSIONS}

1. Using basic equations of surface physics and thermodynamics of nonequilibrium processes we developed a mathematical model to determine the physical quantities characterizing the redistribution of conduction electrons (related charges) and mechanical stress in the surface layer of metal (semiconductor) which correspond them. The presented model takes into account the condition of the dynamic quasiequilibrium of conduction electrons (related charges) in the double electric layer on the metal surface (semiconductor).

2. On the basis of the proposed model we developed the method of determining the physical characteristics of the material which including in the linear state equation (physical equation), the boundary conditions for the chemical potential $\Phi_{0}$ (metal) $\left(Z_{c}\right.$ (for semiconductor)) and mechanical stress $\sigma_{x}$.

3. Also we determined the most important physical quantities for metal surface - capacitance of the double layer $C$ and the Galvani potential $\Delta \Psi$, which can be used to diagnose structural elements in aggressive environments, as well as to determine the energy characteristics of the surface and interphase layers. 


\title{
Механо-електричні характеристики приповерхневих шарів деяких матеріалів
}

\author{
В.М. Юзевич ${ }^{1}$, Б.П. Коман ${ }^{2}$, Р. Джала ${ }^{1}$ \\ 1 Фізико-механічний інститут НАН Украӥни імені Григорія Карпенка, \\ вул. Наукова, 5, 79601 Львів, Україна \\ 2 Львівський національний університет імені Івана Франка, вул. Драгоманова, 50, 79005 Львів, Украйна
}

\begin{abstract}
На основі запропонованої математичної моделі розраховані механоелектричні характеристики приповерхневого шару твердого тіла, що входять у лінійні рівняння стану та зв'язують параметри стану. Представлена модель враховуе умову квазірівноваги електронів провідності (зв'язаних зарядів) у подвійному електричному шарі на поверхні твердого тіла. Уперше для низки матеріалів: $\mathrm{Cr}, \mathrm{W}, \mathrm{Gd}$, $\mathrm{Hf}, \mathrm{Pd}, \mathrm{Mg}$, Ta, Sm, Si, Cu визначено найбільш важливі фізичні величини для поверхні - поверхневий та міжфразовий заряд $\Omega$, електростатичну складову поверхневої енергії $\gamma_{e}$, товщину поверхневого шару $h$, емність подвійного електричного шару $C$ і потенщіал Гальвані $\Delta \Psi$. Ці величини можна використати для діагностики елементів конструкщій в агресивних середовищах та визначення змін енергетичних характеристик поверхневих і міжфразових шарів.
\end{abstract}

Ключові слова: Моделювання, Механічні напруги, Механоелектричні процеси, Поверхневий шар.

\section{Механо-электрическиехарактеристики приповерхносных слоев некоторых материаллов}

\author{
В.Н. Юзевич ${ }^{1}$, Б.П. Коман ${ }^{2}$ Р. Джала ${ }^{1}$ \\ 1 Физико-механический институт НАН Украины илени Григория Карпенко, \\ ул. Научная, 5, 79601 Львов, Украина \\ 2 Львовский национальный университет имени Ивана Франко, ул. Драгоманова, 50, 79005 Львов, Украина
}

\begin{abstract}
На основе предложеной математической модели рассчитаны механоэлектрические характеристики приповерхностного слоя твердого тела, входящие в линейные уравнения состояния и которые связывают параметры состояния. Представленная модель учитывает условие квазиравновесия электронов проводимости (связаных зарядов) в двойном әлектрическом слое на поверхности твердого тела. Впервые для ряда материалов: $\mathrm{Cr}, \mathrm{W}, \mathrm{Gd}, \mathrm{Hf}, \mathrm{Pd}, \mathrm{Mg}, \mathrm{Ta}, \mathrm{Sm}, \mathrm{Si}, \mathrm{Cu}$ определены наиболее важные величины для поверхности - поверхностный и межфазовый заряд $\Omega$, электростатическую составляющую поверхностной энергии $\gamma_{e}$, толщину поверхностного слоя $h$, емкость двойного электрического слоя $C$ и потенциал Гальвани $\Delta \Psi$. Эти величины можно использовать для диагностики элемементов конструкций в агресивных средах и определения знергетических характеристик поверхностных и межфозовых слоев.
\end{abstract}

Ключевые слова: Моделлирование, Механические напряжения, Механоэлектрические процессы, Поверхностный слой.

\section{REFERENCES}

1. C.G. Guymon, R.L. Rowley, J.N. Harb, D.R. Wheeler, Condens. Matter Phys. 8, 335 (2005).

2. D. Bedeaux, S. Kjelstrup, L. Zhu, J.M. Koper, Phys. Chem. Chem. Phys. 2006, 8, (2006)

3. B.P. Koman, V.M. Yuzevich, Phys. Solid State 54, 1335 (2012).

4. B.P. Koman, V.M. Yuzevich, J. Nano-Electron. Phys. 7 No 4, 04059 (2015).

5. D. Bedeaux, Nonequilibrium Thermodynamics and Statistical Physics of Surfaces, Book Series: Advances in Chemical Physics, V. 64 (Eds. I. Prigogine, S.A. Rice) (NJ, USA: 2007).

6. Handbook of Electrochemistry (Ed. by Cynthia G. Zoski) (Amsterdam, The Netherlands: Elsevier, Oxford, UK First edition: 2007).

7. C. Kittel, Introduction to Solid State Physics Seventh ed. (John Wiley \& Sons, Inc.: 2004).

8. W. Greiner, Classical Electrodynamics (New York - Berlin - Heidelberg: Springer-Verlag: 1999).

9. R.D. Hetnarski, J. Ignaczak, Mathematical Theory of Elasticity (New York and London: Published by Taylor \& Francis: 2004).

10. Xionghua Wu, Guofeng Han, Comput. Math. Appl. 61, 2971 (2011).
11. H. Lüth, Solid surfaces, interfaces and thin films, Fifth edition. (Berlin, Heidelberg: Springer-Verlag: 2010).

12. A. Michaelides, M. Scheffler, An introduction to the theory of metal surface, Surface and Interface Science, Concepts and Methods (2010). http://th.fhiberlin.mpg.de/th/publications/Michaelides_Sch efler_Chapter_Submission.pdf.

13. http://dic.academic.ru/dic.nsf/es/35532/

14. http://www.calc.ru/601.html.

15. Yu.A. Klimov, A.S. Kolesnikov, Russ. J. Non-Ferrous Metal. 3, 64 (2006) [in Russian].

16. M. Zenkiewich, J. Achivements Mater. Manufacturing Eng. 24, 137 (2007).

17. https://en.wikipedia.org/wiki/Silicon

18. M.A. Shebzukhova, A.A. Shebzukhov, EPJ Web Conf. 15, 01027 (2011)

19. H.L. Skriver, N.M. Rosengard, Phys. Rev. B 46, 7157 (1992).

20. E.N. Economou, The Physics of Solids, Essentials and Beyond (Berlin, Heidelberg: Springer-Verlag: 2010).

21. T.S. Nahirnyj, Y.A. Senyk, K.A. Tchervinka, Mathematical Modeling and Computing 1 No 2, 214 (2014). 
Table 1 - Physical properties of the surface layers of materials.

\begin{tabular}{|c|c|c|c|c|c|c|c|c|}
\hline \multirow[b]{2}{*}{$N_{z} / n$} & \multirow{2}{*}{$\begin{array}{c}\text { Physical } \\
\text { characteristics }\end{array}$} & \multicolumn{7}{|c|}{ Materils } \\
\hline & & $\mathrm{Mg}$ & $\mathrm{Si}$ & $\mathrm{Cr}$ & $\mathbf{F e}$ & Co & $\mathrm{Cu}$ & Pd \\
\hline 1. & $\Phi_{0}, \mathrm{~V}$ & 3,055 & - & 4,234 & 4,2 & 3,82 & 4,705 & 4,409 \\
\hline 2. & $Z_{0}, \mathrm{~V}$ & - & 5,19 & - & - & - & - & - \\
\hline 3. & $\xi$ & 0,0237 & 0,661 & 1,57 & 0,552 & 0,244 & 0,248 & 0,068 \\
\hline 4. & $b, \mathrm{~V}^{-1}$ & 1,13 & 0,107 & 0,099 & 0,237 & 0,4 & 0,238 & 0,463 \\
\hline 5. & $k \times 10^{10}, \mathrm{~m}^{-1}$ & 1,905 & 1,32 & 1,308 & 2,153 & 2,450 & 1,5 & 1,974 \\
\hline 6. & $\gamma, \mathbf{J} \times \mathrm{m}^{-2}$ & 1,079 & 1,182 & 3,551 & 3,271 & 2,520 & 2,340 & 2,551 \\
\hline 7. & $\gamma_{e}, \mathrm{~J} \times \mathrm{m}^{-2}$ & 0,775 & 0,787 & 2,243 & 2,085 & 1,628 & 1,513 & 1,742 \\
\hline 8. & $\xi \times \gamma_{M}, \mathrm{~J} \times \mathrm{m}^{-2}$ & 0,304 & 0,395 & 1,308 & 1,186 & 0,892 & 0,827 & 0,809 \\
\hline 9. & $\Omega, \mathrm{Cl} \times \mathrm{m}^{-2}$ & 0,362 & 0,303 & 0,509 & 0,63 & 0,594 & 0,448 & 0,552 \\
\hline 10. & $h, \mathrm{~nm}$ & 0,712 & 0,967 & 1,024 & 0,644 & 0,58 & 0,901 & 0,715 \\
\hline 11. & $\mathrm{C}, \mathrm{mF} \times \mathrm{m}^{-2}$ & 84,30 & 58,4 & 57,86 & 95,59 & 108,4 & 66,3 & 87,34 \\
\hline 12. & $\Delta \psi, \mathrm{V}$ & 4,289 & - & 8,805 & 6,616 & 5,481 & 6,751 & 6,316 \\
\hline 13. & $\Delta z, \mathrm{~V}$ & - & 5,19 & - & - & - & - & - \\
\hline 14. & $d=2 / k, \mathrm{~nm}$ & 0,105 & - & 0,153 & 0,093 & 0,816 & 0,133 & 0,101 \\
\hline 15. & $\begin{array}{l}\text { Electronegativity } \\
\text { (Pauling) }\end{array}$ & 1,31 & 1,9 & 1,66 & 1,83 & 1,88 & 1,9 & 2,2 \\
\hline 16. & $\begin{array}{l}\text { Periodic number in the } \\
\text { Periodic } \\
\text { elements }\end{array}$ & 12 & 14 & 24 & 26 & 27 & 29 & 46 \\
\hline
\end{tabular}

Table 2 - Continue

\begin{tabular}{|c|c|c|c|c|c|c|c|c|c|}
\hline \multirow{2}{*}{$\mathbf{N}_{z} / \mathbf{n}$} & \multirow{2}{*}{$\begin{array}{c}\text { Physical } \\
\text { Characteristics }\end{array}$} & \multicolumn{8}{|c|}{ Materils } \\
\hline & & Ag & Sm & Gd & Hf & Ta & $\mathbf{W}$ & $\mathbf{P t}$ & $\mathrm{Au}$ \\
\hline 1. & $\Phi_{0}, \mathrm{~V}$ & 4,34 & 3,89 & 3,37 & 5,91 & 6,78 & 5,045 & 5,75 & 4,963 \\
\hline 2. & $Z_{0}, \mathrm{~V}$ & - & - & - & - & - & - & - & - \\
\hline 3. & $\xi$ & 0,025 & 0,035 & 0,0136 & 0,0525 & 0,0174 & 1,122 & 0,238 & 0,119 \\
\hline 4. & $b, \mathrm{~V}^{-1}$ & 0,6083 & 0,413 & 1,2917 & 0,398 & 0,465 & 0,1023 & 0,138 & 0,2333 \\
\hline 5. & $K \times 10^{10}, \mathrm{~m}^{-1}$ & 1,317 & 1,375 & 1,879 & 1,349 & 1,391 & 1,693 & 1,2095 & 1,536 \\
\hline 6. & $\gamma, \mathrm{J} \times \mathrm{m}^{-2}$ & 1,5517 & 1,571 & 1,289 & 3,425 & 4,638 & 3,680 & 2,775 & 2,018 \\
\hline 7. & $\gamma_{e}, \mathrm{~J} \times \mathrm{m}^{-2}$ & 1,0857 & 1,010 & 0,936 & 2,376 & 3,313 & 2,369 & 1,805 & 1,333 \\
\hline 8. & $\xi \times \gamma_{M}, \mathrm{~J} \times \mathrm{m}^{-2}$ & 0,466 & 0,561 & 0,353 & 1,049 & 1,325 & 1,311 & 0,969 & 0,685 \\
\hline 9. & $\Omega, \mathrm{Cl} \times \mathrm{m}^{-2}$ & 0,3557 & 0,351 & 0,3945 & 0,5326 & 0,639 & 0,596 & 0,439 & 0,382 \\
\hline 10. & $h, \mathrm{~nm}$ & 1,058 & 0,932 & 0,737 & 1,027 & 1,072 & 0,815 & 1,117 & 1,065 \\
\hline 11. & $\mathrm{C}, \mathrm{mF} \times \mathrm{m}^{-2}$ & 58,3 & 60,86 & 83,167 & 59,69 & 61,56 & 74,92 & 53,39 & 54,69 \\
\hline 12. & $\Delta \psi, \mathrm{V}$ & 6,104 & 5,760 & 4,744 & 8,923 & 10,38 & 7,952 & 8,223 & 6,983 \\
\hline 13. & $\Delta z, \mathrm{~V}$ & - & - & - & - & - & - & - & - \\
\hline 14. & $d=2 / R$ & 0,152 & 0,145 & 0,1064 & 0,148 & 0,144 & 0,118 & 0,166 & 0,162 \\
\hline 15. & $\begin{array}{l}\text { Electronegativity } \\
\text { (Pauling) }\end{array}$ & - & 1,17 & 1,2 & 1,3 & 1,5 & 1,77 & 2,2 & 2,4 \\
\hline 16. & $\begin{array}{l}\text { Periodic number in } \\
\text { the Periodic system } \\
\text { of elements }\end{array}$ & - & 62 & 64 & 72 & 73 & 74 & 78 & 79 \\
\hline
\end{tabular}

The abbreviations usedin this table are the following : $\Phi_{0}$ - equilibrium chemical potential of the electrons in the volume of solids; $Z_{0}$ - the chemical potential of particles that correspond bound electrical charge in a semiconductor; $\xi$ dimensionless coefficient that describes change in surface energy by changing the mechanical component of surface energy $\left(\gamma_{e}+\xi \gamma_{M}=\left.\gamma \Rightarrow \frac{\partial \gamma}{\partial \gamma_{M}}\right|_{\gamma_{e}=\text { const }}=\xi\right)$; $b$ - electrostrictive coefficient of volume expansion; $k$ - value, which inverse to distance at which space charge in the surface layer varies in $e$ - times. The components of surface energy: $\gamma_{e}$ - electrical component, $\bar{\xi} \times \gamma_{m}$ - mechanical component; $\Omega-$ surface charge; $h$ - the thickness of the surface layer; $C$ - the capacity of the double surface layer; $\Delta \Psi$ - Galvani potential; $\Delta Z$ - difference of the potentials of double electric layer on the semiconductor surface (corresponds to related charges); $d=2 / k$ - the distance between plates of the surface capacitor. 